\title{
A CASE OF BRONCHIAL ADENOMA WITH LIVER METASTASIS \\ BY
}

\author{
PRISCILLA KINCAID-SMITH AND JEAN-JACQUES BROSSY
}

\begin{abstract}
From the Departments of Pathology and Surgery, Hammersmith Hospital (Postgraduate Medical School of London)
\end{abstract}

(RECEIVED FOR PUblication aUgust 19, 1955)

Distant metastases from bronchial " adenomas" are sufficiently uncommon to warrant reporting a patient in whom a liver metastasis after apparently successful treatment of a bronchial adenoma caused diagnostic difficulties.

\section{CASE REPORT}

A shorthand-typist, then aged 58 , was first seen in February, 1948, complaining that three months previously she had caught a cold which had "gone into her chest" and persisted, with the development of a cough productive of sputum which had latterly been blood-streaked.

Clinical examination suggested some collapse at the right lung base, and radiography of the chest confirmed that this involved mainly the middle lobe. At bronchoscopy a large polypoid tumour was found in the right main bronchus, just above the middle lobar and apical lower segmental orifices. A biopsy specimen was reported as bronchial adenoma. A right middle and lower lobectomy was performed (March, 1948). Convalescence after this operation was smooth.

At a routine follow-up visit in September, 1954, the patient reported having had intermittent diarrhoea for 10 weeks, the stools being watery, without blood or slime. She had also suffered flatulence associated with colicky rumblings in the upper abdomen. There was no history of dyspepsia, pain, or weight loss.

Palpation of the abdomen showed a mobile, smooth, rounded tumour about $10 \mathrm{~cm}$. in diameter projecting from under the left costal margin near the midline. It moved freely on respiration and could be pushed from side to side of the abdomen. There was no associated tenderness or pain.

A few rales were audible over the right lung, and the trachea was slightly displaced to the right, but air entry on both sides of the chest was good and radiography confirmed the absence of gross disease in the chest.

A barium meal and enema showed that the stomach and colon were displaced by but not attached to the mass, which appeared to be in a more posterior plane. An intravenous pyelogram showed that the left kidney was displaced downwards, but the caliceal pattern was normal.
Our presumptive pre-operative diagnosis was of a pancreatic cyst, but at laparotomy (through a left upper paramedian incision) a cystic mass was found, $10 \mathrm{~cm}$. in diameter, in the lower edge of the left lobe $z$ of the liver. This was thought to be a simple cyst of the liver, and easily excised with a thin rim of liver $\stackrel{\rho}{\mathcal{S}}$ tissue. There were no other tumours in the liver, and the stomach, transverse colon, and gall bladder $\mathscr{E}$

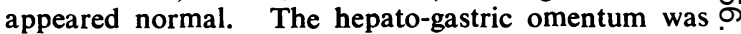
abnormally large and lax. This and the unusual 0 mobility of the tumour clearly enabled it to project behind the stomach and give the radiological appearance of a retroperitoneal mass.

The patient was fit and well when last seen in March, 1955 , aged 65 .

\section{MORBID ANATOMY}

Bronchial Adenoma.-This was excised in 1948. The right middle lobe bronchus forked into medial and lateral branches $15 \mathrm{~mm}$. below its origin. The main tumour mass was in the medial branch of the middle lobe bronchus. It measured $11 \mathrm{~mm}$. in diameter and extended over a length of approximately $35 \mathrm{~mm}$. Tumour was also present in the lumen of 3 the main middle lobe bronchus and its lateral branch. The main tumour mass had invaded the surrounding lung through the wall of the bronchus, and extended along the branches of the medial bronchus. The whole 음 middle lobe was collapsed. The tumour tissue was $\rightarrow$ soft, friable, and homogeneous. It was buff-coloured and showed no macroscopic haemorrhage or necrosis.

Histology.-The tumour (Fig. 2) consisted of uniform polyhedral cells $15-20 \mu$ in diameter with $\mathcal{N}$ granular pale eosinophilic cytoplasm and oval or $\mathbb{\omega}^{-}$ spherical vesicular nuclei. Very occasional mitoses were observed.

The arrangement of cells in most areas was into small regular groups 20-50 cells across. These were $\mathscr{\odot}$ separated by a delicate stroma rich in vascular chan- + nels. In other areas sheets and columns of cells $\frac{T}{T}$ were less regularly permeated by a similar delicate $\stackrel{\vec{D}}{\stackrel{P}{D}}$ vascular stroma. Within a bronchial lumen in one $\stackrel{\mathbb{\rho}}{\mathscr{Q}}$ area there was a definite papillary pattern.

From the tumour in the medial branch of the middle lobe bronchus the surrounding lung was extensively 
invaded. Active destruction of cartilage and invasion of lymphatics was observed. In addition distant bronchioles and alveoli contained small groups of living tumour cells quite separate from the main tumour. A diagnosis of carcinoid type of bronchial adenoma was made.

The Liver Tumour.-This was excised in 1954. Externally this was a smooth oval apparently cystic mass (Fig. 3) measuring $111 \times 100 \times 65 \mathrm{~mm}$. and weighing $500 \mathrm{~g}$. The upper half of the tumour was covered by a 2-3 mm. shell of liver tissue. The lower surface showed "sugar-icing" thickening of the peritoneum.

On section a fibrous capsule $0.5-1 \mathrm{~mm}$. thick surrounded the tumour. In the fresh state the latter was extraordinarily soft, resembling semi-solid gelatine. It had a spongy appearance due to the presence of abundant large and small haemorrhagic areas. The tumour tissue was buff coloured. No areas of necrosis were present.

Histology.-The microscopical appearance (Fig. 4) was very similar to that of the primary bronchial adenoma removed six years previously. In the solid areas the cells were uniformly arranged in small groups separated by delicate vascular stroma. In other areas large irregular cystic spaces containing blood or lymph separated the cell groups.

The tumour cells were of the same uniform polyhedral type described above. The only significant difference was the relative frequency of mitoses which were approximately one per high power field $(0.05$ sq. $\mathrm{mm}$.). The dense collagenous capsule was invaded

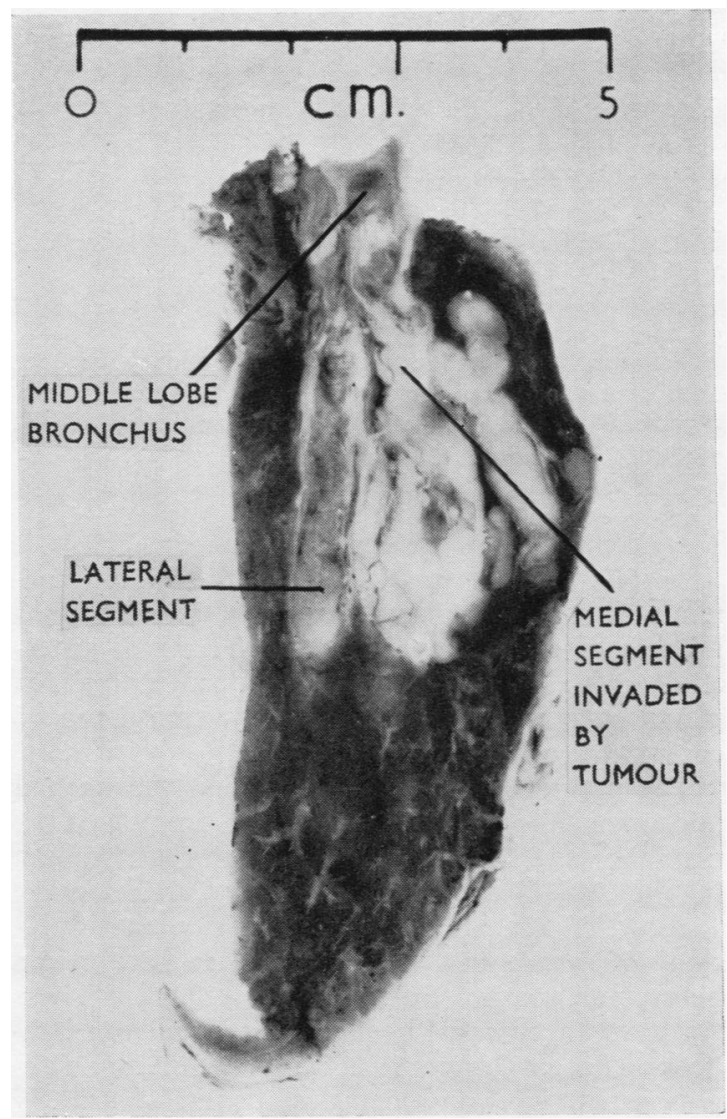

Fig. 1.-Photograph of right middle lobe in section.

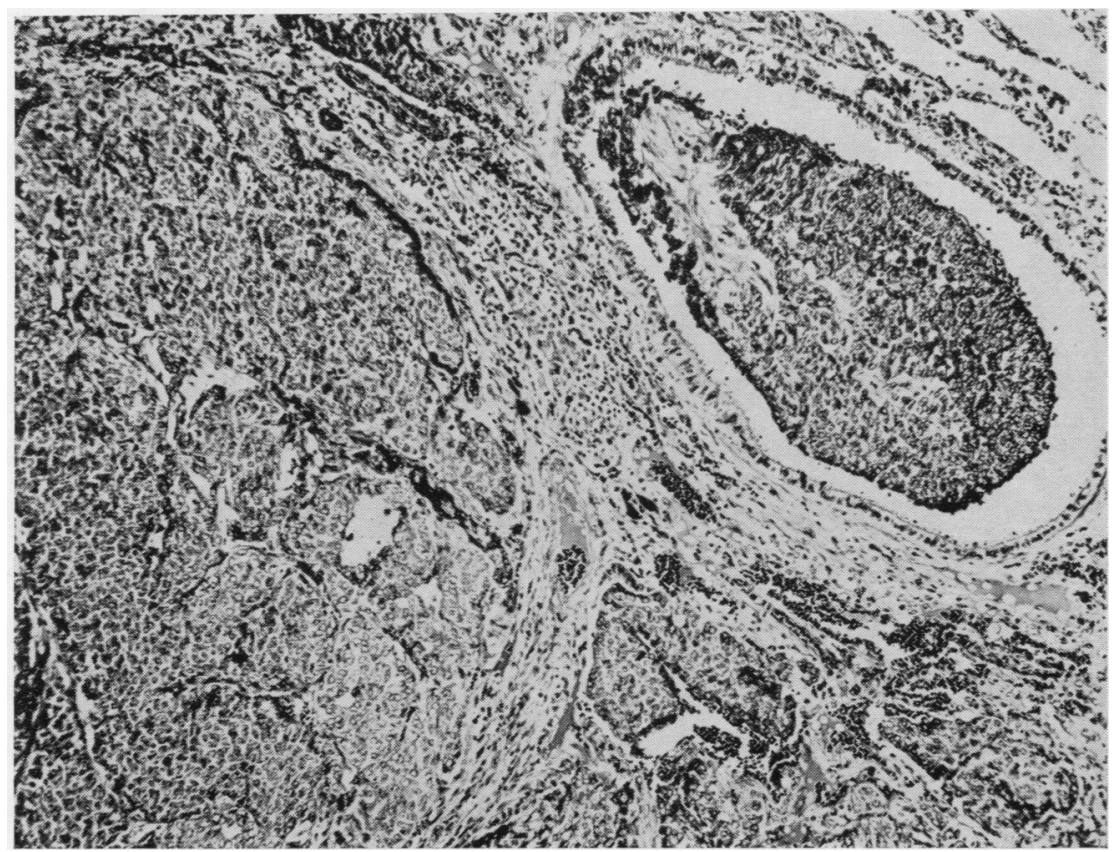

FIG. 2.-Photomicrograph o bronchial adenoma showing tumour growth in the lumen of a bronchus and in the surrounding lung parenchyma $(\times 90)$. 
at several points. In addition a few scattered groups of infiltrating tumour cells were present in the adacent liver tissue outside the capsule.

This tumour was diagnosed as a metastatic deposit from the carcinoid bronchial adenoma removed six years previously.

\section{METHODS}

Sections from both primary and secondary tumour were stained by the diazo method for argentaffin cell granules (Pearse, 1953) and by the periodic-acid-Schiff method for mucin. Both methods gave negative results.

\section{Discussion}

In spite of the invasive character and the occurrence of local lymph node and distant metastases in tumours of the type described above, it is generally agreed that there is every justification for placing them in a separate category from the more common bronchial carcinomas.

The natural history of the so-called "bronchial adenomas" is strikingly different from that of carcinomas. The adenomas are most common in the 30-40 age group (Foster-Carter, 1941; Liebow, 1952) and in the majority the duration of symptoms is as long as five years before diagnosis (Foster-Carter, 1941). These features, together with an almost equal sex incidence (Foster-Carter, 1941 ; Liebow, 1952), sluggish growth, and rare metastases, contrast strongly with those of bronchial carcinoma.

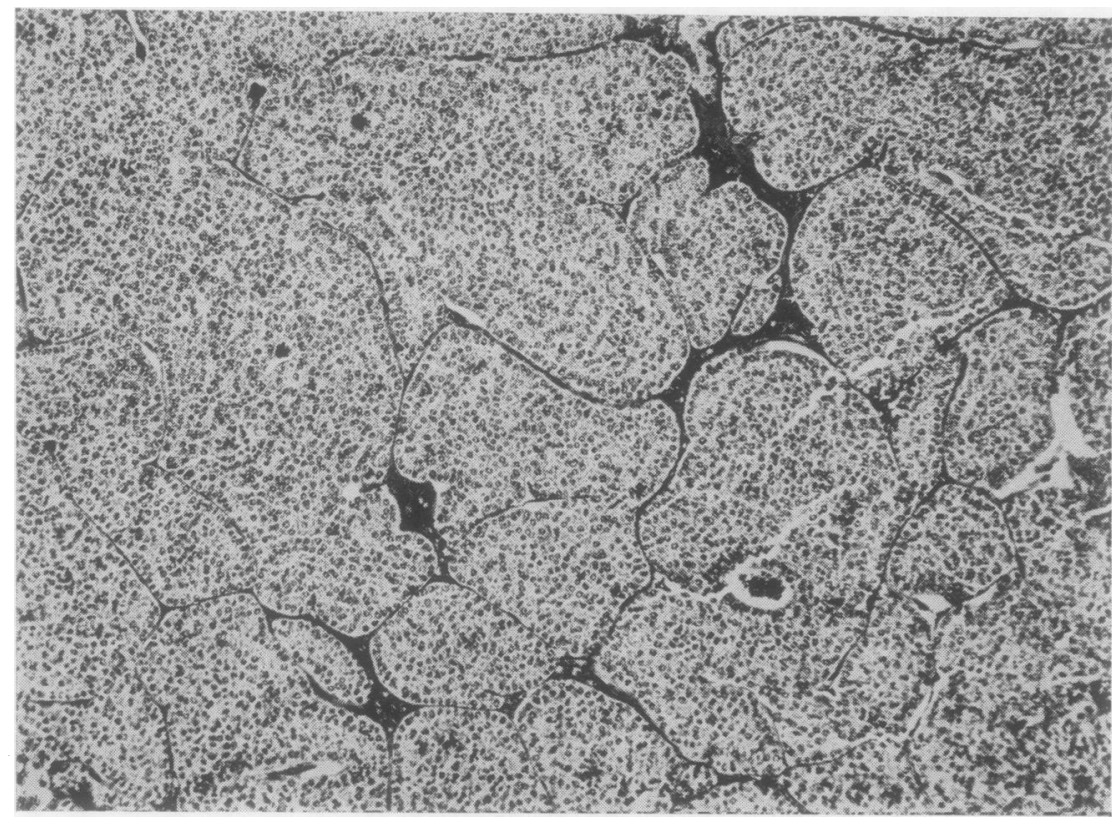

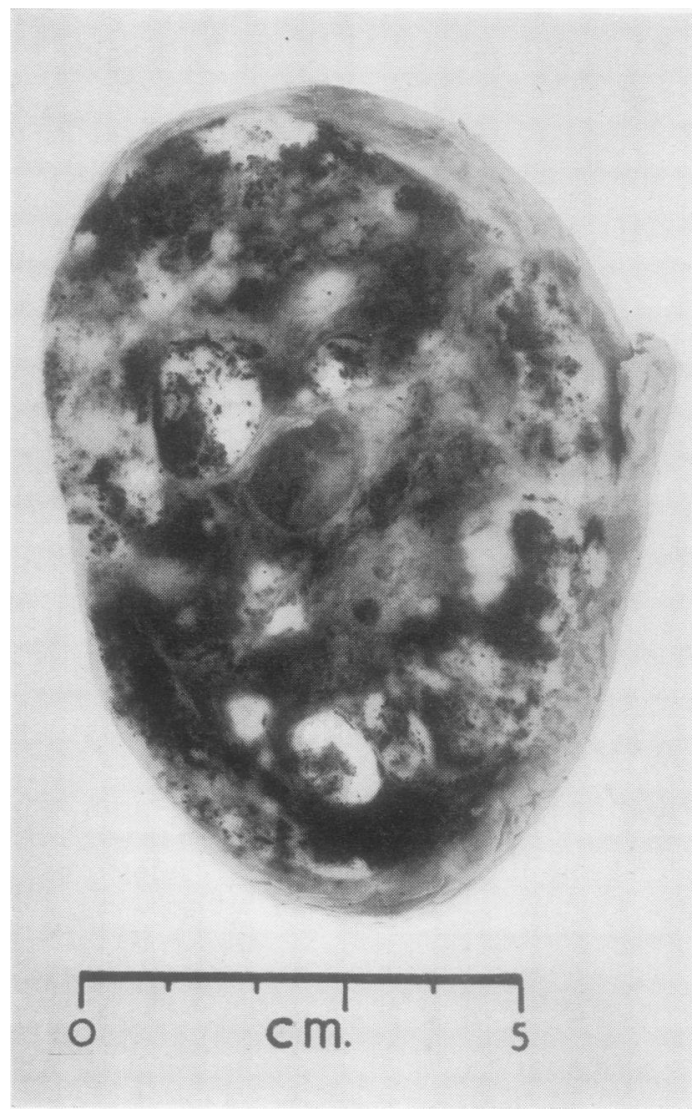

FIG. 3.-Macroscopic appearance of the liver "cyst" on section. A small tag of normal liver tissue is seen on the right side.

FiG. 4.-Photomicrograph of a section from the liver tumour. The! appearances are those of a carcinoid type of tumour $\triangle$ ( $\times 90)$. 
Structural Types.-The descriptive terms carcinoid and cylindroma have been widely applied to the two main histological types of bronchial adenoma. Liebow (1952) states that $85 \%$ are of the carcinoid type and $15 \%$ of the cylindroid.

The carcinoid type owes its name to the striking similarity between these tumours and the argentaffinoma (carcinoid) of the intestine. The description given above covers most of the classical features of this type. The arrangement is not acinar but in groups of cells separated by delicate highly vascular stroma. A pseudo-acinar picture may be produced by the survival of a ring of cells around a vessel.

The choice of the name cylindroma is perhaps less fortunate than that of carcinoid. The classical arrangement here is that of branching tubular epithelial structures frequently with a double lining. The rather irregular acini are lined by small, deeply staining cells, more variable in size and shape than in the carcinoid type. Microscopically the tumour appears more invasive than the carcinoid, and mucin secretion is frequently seen.

Mitoses are rare in both types but more frequent in the cylindromas. Haemorrhagic areas are more common in the carcinoid, and necrosis very rarely occurs in either histological type.

In addition to these two main types of bronchial adenoma minor variations in the histological picture may occur. Tumours may be composed almost entirely of " oncocytes." Like the oncocytic (Hürthle) thyroid adenomas and salivary tumours the cells in this type have a large amount of opaque eosinophilic cytoplasm and a dense nuclear chromatin. Their arrangement is usually similar to that seen in carcinoids, but oncocytic areas may occur in either type. A further variation usually seen in the cylindroma has been called muco-epidermoid (Liebow, 1952) because of the presence of mixed mucous and squamous areas.

Nomenclature and Histogenesis.-The name bronchial adenoma is so widely accepted for this group of tumours that we think it should be retained in spite of their malignant potentialities.

Willis (1953) regards bronchial adenomas as analogous to the pleomorphic (mixed) salivary tumours and considers that they arise from the mucous glands of the bronchial wall. He does not subdivide them into histological types. Womack and Graham (1938) consider them to be tumours of mixed developmental origin on the basis of areas of bone cartilage and mucous glands within them. Willis (1953) and others (Doty, 1951 ; Van Hazel, Holinger, and Jensik, 1949 ; Moersch, Tin- ney, and McDonald, 1945) consider that the bone arises from stromal metaplasia and the cartilage and glands from invasion of bronchial wall structures. Womack and Graham (1938) group all bronchial adenomas together as mixed tumours of lung. Holley (1946), Goldman (1949), and Doty (1951) have all used the term " mixed tumour" for the non-carcinoid (cylindroma) group of bronchial adenomas. Van Hazel and others (1949) use the name "adenoma" for the carcinoid type alone and cylindroma for the residue.

Because of this confusion in nomenclature it seems to us desirable to employ a purely descriptive classification such as that of Liebow (1952). He divides bronchial adenomas into the two characteristic patterns carcinoid and cylindroid (cylindroma), and recognizes the occurrence of oncocytoid and muco-epidermoid variants within these two groups. This avoids the use of the terms " mixed tumour" and "adenoma" to which different meanings have been applied by different authors.

Behaviour of Different Types.-The justification for subdividing bronchial adenomas depends on the differences in behaviour and thus in prognosis in the two types. It appears that the data at present available are insufficient for an accurate assessment of the liability of the types of bronchial adenoma to invade and metastasize (Liebow, 1952). It will be difficult to obtain this information until a standard nomenclature is adopted.

As recently as 1941 Foster-Carter stated that distant metastases from these tumours were unknown. To-day, however, their occurrence is well recognized (Mallory, 1938 ; Adams, Steiner, and Bloch, 1942 ; Anderson, 1943 ; Laff and Neubuerger, 1944; Holley, 1946; Van Hazel and others, 1949 ; Liebow, 1952). Locally the cylindroma shows a more invasive microscopic picture than the carcinoid, more frequently invading cartilage and vessels (Liebow, 1952). Several authors regard cylindromas as probably more malignant than carcinoids (Laff and Neubuerger, 1944 ; Van Hazel and others, 1949 ; Goldman, 1949). It is worthy of note that few distant metastases from cylindromas have been reported (Van Hazel and others, 1949 ; Liebow, 1952). In most reported cases of haematogenous spread the tumour has been of the carcinoid type. This apparent discrepancy may be due to the relative infrequency of cylindromas, which constitute only some $15 \%$ of all bronchial adenomas (Liebow, 1952).

The tumour in our case clearly falls within the carcinoid group. We were unable to demonstrate 
argentaffin granules in the tumour. These were reported in one case by Holley (1946).

In 1943 Anderson reported the first macroscopic metastasis from a bronchial adenoma. This was a $2 \mathrm{~cm}$. nodule in the liver, and no other metastases were found at the necropsy. Several other authors have reported liver metastases (Adams and others, 1942 ; Laff and Neubuerger, 1944 ; Holley, 1946 ; Graham, 1949). Gordon (1949) had a case very similar to ours in which a tumour removed from the left lobe of the liver was found to be identical with a bronchial adenoma removed previously. The time interval is not stated.

In our case six and a half years elapsed between lobectomy for the bronchial adenoma and the symptoms which led to the discovery of an abdominal tumour. The metastatic deposit was histologically very similar to the bronchial tumour. The length of history and well-formed capsule around the liver tumour indicate that growth was very slow. At the time of removal, however. mitoses were undoubtedly more numerous in the metastasis than in the primary tumour. This is of interest in view of reports of the progression of bronchial adenomas to frank carcinomas (Bigger, 1945; Alexander, 1945; Cheek and Muirhead. 1948 : Goldman, 1949 ; Abbott, 1949 ; Umiker and Storey, 1952 : Price Thomas, 1954). Willis (1953) discusses two cases in which the diagnosis lay between an adenoma and a carcinoma. It is possible that malignant transition may account in part for the rarity of necropsy accounts of bronchial adenoma in the days before bronchoscopy became a routine method of investigation.

\section{SUMMARY}

A case of adenoma of the bronchus is presented. in which a metastasis appeared in the liver six years after excision of the original tumour by lobectomy. The common origin of both tumours is demonstrated histologically, and the experiences of other authors with distant metastases in these tumours are briefly reviewed. A plea is made for simplification and standardization of nomenclature.

We thank Mr. W. P. Cleland and Mr. R. H. Franklin for permission to publish this case. and Professor C. V. Harrison for his helpful advice. The histological material was prepared by Mr. J. G. Griffin and photographed by Miss R. Klein.

\section{REFERENCFS}

Abbott, O. (1949). J. thorac. Surg.. 18, 156

Adams, W. E., Sieiner, P. E., and Bloch, R. G. (1942). Surgery, 11. 503 .

Alexander, J. (1945). J. thorac. Surg.. 14, 122

Anderson, W. M. (1943). 1bid., 12, 351 .

Bigger, I. A. (1945). Ibid., 14, i20.

Bigger, I. A. (1945) Muir., 14, 120 . (1948). Arch. Path. (Chicago), 46. 529 .

Doty, R. D. (1951). J. thorac. Surg., 21. 349.

Fosier-Carter. A. F. (1941). Quari. J. Mled.. 10. 139.

Goldman. A. (1949). J. thorac. Surg., 18, 137.

Gordon, J. (1949). Ibid., 18. 158.

Graham, E. (1949). Ibid.. 18. 155.

Holley, S. W. (1946). Milit. Surg.. 99. 528

Laff, H. I., and Neubuerger, K. T. (1944). Arch. Oiolaryng. (Chicago), 40. 487.

Lietow A. A. (1952). Tumors of the Lower Respiratory Tract. Atlas of Tumor Pathology. Section V. Fascicle 17. Armed Forces Institute of Pathology. Washington.

Mallory, T. B. (1938). New Engl. J. Med.. 218. 391.

Moersch. H. J., Tinney, W. S., and McDonald, J. R. (1945). Surg. Gynec. Obstet. 81. s5i.

Pearse. A. G. E. (1953). Histochemistry. Theoretical and Appiict. p. 477. Churchill, London.

Thomas, C. P. (1954). Lancet. 1.1.

Umiker, W.. and Storey, C. F. (1952). J. thorac. Surg.. 24.420.

Van Hazel. W.. Holinger, P. H., and Jensik, R. J. (1949). I Dis. Chest. 16. 146.

Willis, R. A. (1953). Pathology of Tumours, 2nd ed. Butterworth, London.

Womack. N. A., and Graham. E. A. (1938). Arch. Path. (Chicago), 26. 165 . 